\title{
Analysis of Diagnosis Delay on Lung Tuberculosis Patient in Porong's Primary Health Care, East Java, Indonesia
}

\author{
Muhammad Bagus ${ }^{1}$, Budiono ${ }^{2}$, Soedarsono $^{3}$ \\ ${ }^{1}$ Faculty of Medicine, Unair, Surabaya, Indonesia \\ 2 Department of Public Health, Faculty of Medicine, Unair, Surabaya, Indonesia \\ ${ }^{3}$ Department of Pulmonology and respiration Medicine, Faculty of Medicine, Unair, Surabaya, Indonesia
}

\section{ARTICLE INFO}

Article history:

Received 09 February 2021

Received in revised form 29

May 2021

Accepted 30 May 2021

\section{Keywords:}

Tuberculosis Epidemiology, Diagnosis delay,

Patient delay,

System delay.

\begin{abstract}
Introduction: The duration of diagnosis delay in tuberculosis (TB) control strategy is one of the problems in TB control program. There are a lot of adverse effects, such as increasing the risk of people to become more prone to TB transmission, infectivity period, and worsening the patient's condition that can furthermore increase the mortality and morbidity numbers. This study aimed to analyze the delay behavior in the society, specifically in Porong, East Java.

Methods: The respondents filled a questionnaire, the answer was crosschecked and complemented with the medical record on the clinic. The data collected then were analyzed with binary logistic regression using SPSS.

Results: From the total of 22 samples in this study, 11 of them were classified to be delayed (patients checked their symptoms 2 weeks after the symptoms started to appear). Some factors that might have an effect on the patient's delay were education level, the patient's knowledge about TB, and occupation that lead to the patient's business. Meanwhile, factors like age, gender, and the distance between the patient's house and the health facility might have an insignificant effect.

Conclusion: Duration of patient delay contributed significantly to the duration of diagnosis delay, with the median duration of 29 days. Meanwhile, the duration of system delay that was found only ranging at 0-3 days. In this study, however, evidence of the independent factors might have an effect on the patient's tendencies to delay treatment that had not yet proven by statistical analysis.
\end{abstract}

\section{INTRODUCTION}

Infectious disease caused by Mycobacterium tuberculosis is still an important problem in several countries. Tuberculosis (TB) is the ninth highest cause of death in the world and the prominent cause of death due to a single infection, beating HIV/AIDS. ${ }^{1}$ Indonesia is among the countries with a dangerous and high prevalence number of $\mathrm{TB}$ since it includes a large number of TB patients, TB patients with HIV, and TB patients with drug-resistant. ${ }^{2}$ The incidence rate of TB patients in East Java in 2015 was the second highest in Indonesia, with $56 \%$ of case detection rate. ${ }^{3}$ The case detection rate was still not reaching the predefined target of $70 \%$. This number was quite low, meaning there were still plenty of TB suspects that were still not identified yet, it could make the disease keep on spreading. Diagnosis delay of TB patients is one of the factors that causes a high number of TB patients.

There are two factors that contribute to the diagnosis delay, the patient delay and the system delay. The duration of patient delay is counted from the day that the patient started to feel the symptoms until they went to the health facility called Pimary Health Care (PHC). The duration of system delay is counted from the day the patient went to the health facility until the TB treatment started. ${ }^{4}$ The duration of diagnosis delay is the accumulation of these two factors combined.

*Corresponding author: andrafidi@gmail.com 
There are plenty of factors that contribute to patient delay, but the dominant factors are the patient that thinks the disease will heal automatically, economy problems, bustle, and difficult access to reach the health facilities. ${ }^{5}$ The causes of the system delay are various factors that cause the health facility taking more time to start the treatment. Diagnosis delay can increase the risk of TB transmission, infectivity period, severity, mortality, and morbidity. ${ }^{4,6,7}$

\section{METHODS}

This study used analytic observational methods, the data was collected without any intervention, then was processed with binary logistic regression method using SPSS. This study aimed to determine factors that could affect the diagnosis delay of the sample. The data used was a questionnaire which was filled by the patients and the medical record of TB clinic in Porong's Primary Health Care (PHC). The answers of the questionnaire were used to determine the patient's characteristics and the duration of the patient delay, while the medical records were used to check the system delay. The population involved in this study was lung TB patients who were being treated at TB polyclinic in Porong's PHC. The samples were the patients that were treated from January until March 2019 using the total sampling method. The inclusion criteria were patients diagnosed with lung TB Acid Fast Bacilli (AFB) positive, diagnosed positive via molecular rapid test, and lung TB positive with drug-resistant. The exclusion criteria were patients with extrapulmonary TB, patients who did not want to cooperate, patients who were treated beyond the research timeline, and children. The independent factors enlisted were: patient's identity (includes gender, age, education, and occupation); access to $\mathrm{PHC}$ (includes the distance travelled between the patient's house to PHC and the time needed); and the knowledge of TB. The dependent variables were the system delay and patient delay that occurred.

\section{RESULTS}

There were 22 samples in this study, consisted of 11 male patients and 11 female patients. The majority of the patients were high school graduates with 13 people, followed by junior high school graduates and elementary school graduates. The majority of the patients were entrepreneurs with 8 people, followed by unemployed, private employees, and students with 7 people, 4 people, and 3 people respectively (Figure 1).

In this study, the youngest patient was 15 years old, and the oldest was 68 years old. The majority of the patient's house was less than $7 \mathrm{~km}$ away from Primary Health Care. Meanwhile, the furthest patient lived $15 \mathrm{~km}$ away from Primary Health Care. The majority of the patients (12 people) needed 11-20 minutes for the travel. However, there were 5 people who needed 21-30 minutes. The patient's knowledge level was showed that they have an "enough" knowledge (Table 1).

In this study, it was found that the median patient delay interval was 29 days. The longest patient delay duration was 16 weeks, and the shortest was within 1 week of delay. The diagnosis delay interval data was obtained from the answers of the questionnaire, which were crosschecked and complemented with data from the TB clinic of PHC. The system delay interval was divided into three parts, namely the interval between the patient came to the clinic - the sputum sample collected by the lab; the sample collected - the result came out; between the result came out - the treatment started (Figure 2).

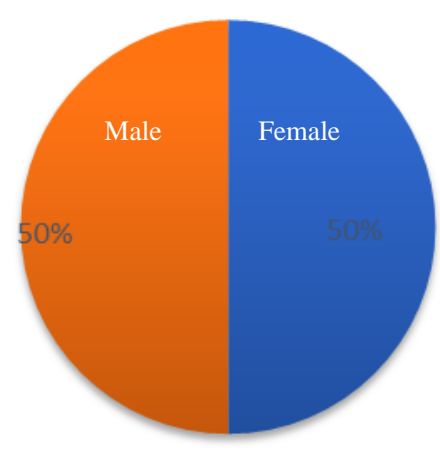

Patient's Gender

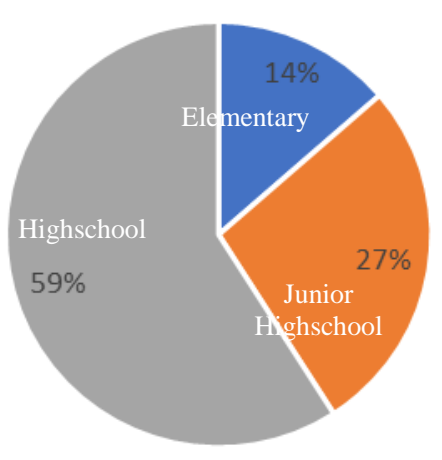

Education Level

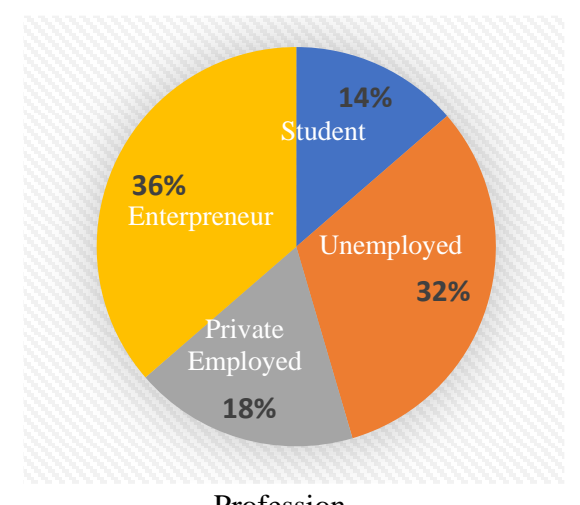

Profession

Figure 1. Distribution of Patients' gender, education level, and profession 

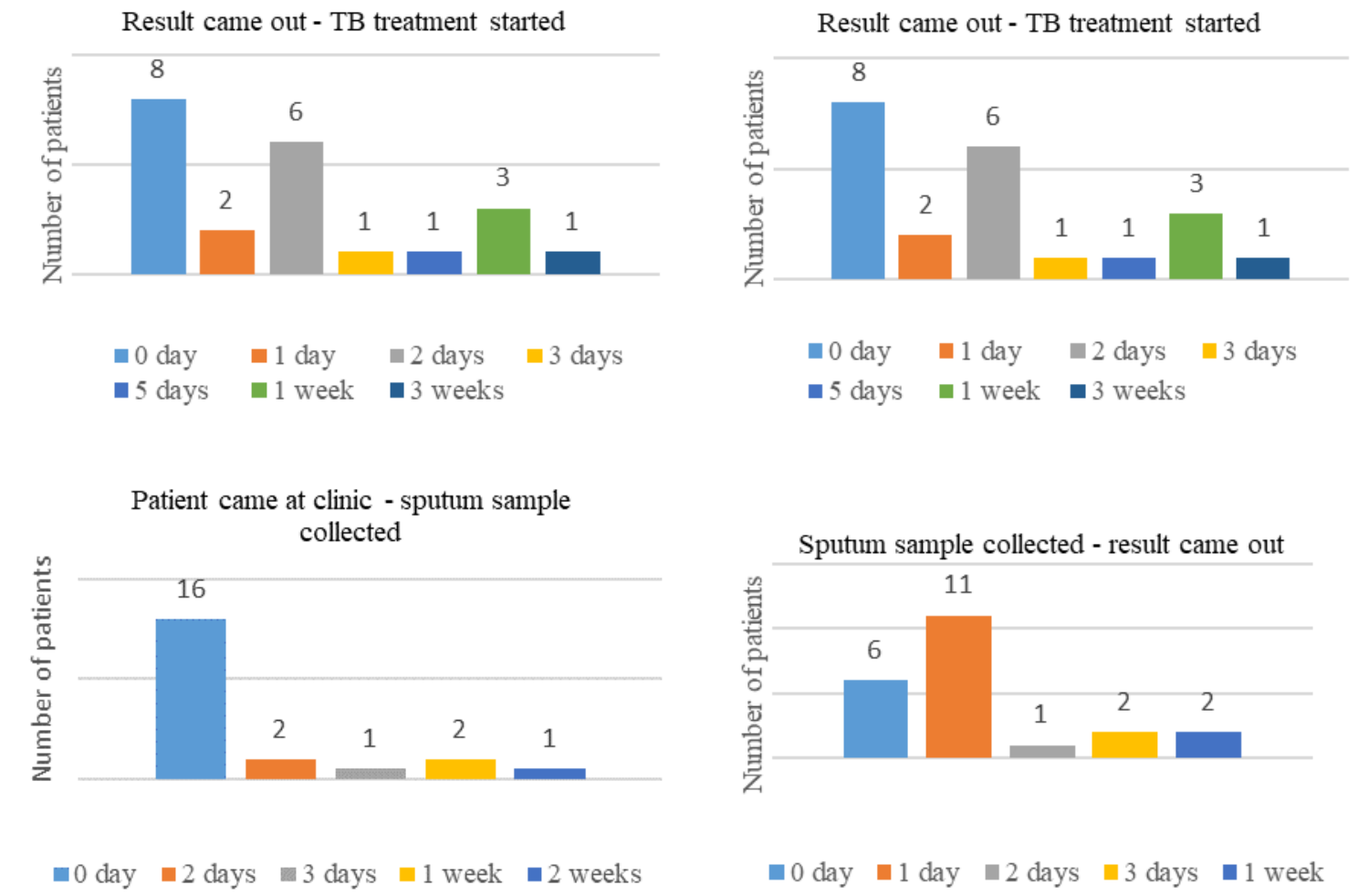

Figure 2. Patient delay duration, Distribution of interval duration between result came out - TB treatment started, Distribution of interval duration between patient came at the clinic - sputum sample collected, Distribution of interval duration between patient sputum sample collected - result came out

Table 1. Distribution of Age, Distance, Durations, an patient's knowledge levels

\begin{tabular}{lcc}
\hline Variables & $\mathrm{n}$ & Percentage (\%) \\
\hline Age (years old) & & \\
- $10-20$ & 3 & 13.6 \\
- $21-30$ & 4 & 18.2 \\
- $31-40$ & 3 & 13.6 \\
- $41-50$ & 4 & 18.2 \\
- $51-60$ & 4 & 18.2 \\
- $>60$ & 4 & 18.2 \\
Distance & & \\
- $0-4$ km & 9 & 40.9 \\
- 5-7 km & 8 & 36.4 \\
- $>7$ km & 5 & 22.7 \\
Duration & & \\
- $0-10$ minutes & 5 & 22.7 \\
- $11-20$ minutes & 12 & 54,6 \\
- 21-30 minutes & 5 & 22.7 \\
Patients' knowledge & & \\
level & & 18.2 \\
- Good & 4 & 63.6 \\
- Enough & 14 & 18.2 \\
- Lacks & 4 & \\
\hline
\end{tabular}

Table 5. Distribution between the delayed group and non-

\begin{tabular}{|c|c|c|}
\hline Variables & $\begin{array}{c}\text { Non-delay } \\
(\leq 2 \text { weeks }) \\
n=11\end{array}$ & $\begin{array}{c}\text { Delay } \\
(>2 \text { weeks }) \\
n=11\end{array}$ \\
\hline \multicolumn{3}{|l|}{ Age } \\
\hline Youngest & 17 years old & 15 years old \\
\hline Oldest & 68 years old & 61 years old \\
\hline Median & 41.3 years old & 40.5 years old \\
\hline \multicolumn{3}{|l|}{ Gender } \\
\hline Male & 5 & 6 \\
\hline Female & 6 & 5 \\
\hline \multicolumn{3}{|l|}{ Education (graduates) } \\
\hline Elementary school & 1 & 2 \\
\hline Junior highschool & 1 & 5 \\
\hline Highschool & 9 & 4 \\
\hline \multicolumn{3}{|l|}{ Occupation } \\
\hline Unemployed/housewive & 3 & 4 \\
\hline Student & 1 & 2 \\
\hline Private employee & 1 & 3 \\
\hline Entrepreneur & 6 & 2 \\
\hline \multicolumn{3}{|l|}{ House distance } \\
\hline Near $(0-4$ km) & 5 & 4 \\
\hline Medium (5-7 km) & 4 & 4 \\
\hline $\operatorname{Far}(>7 \mathrm{~km})$ & 2 & 3 \\
\hline Median & $5.3 \mathrm{~km}$ & $5.1 \mathrm{~km}$ \\
\hline \multicolumn{3}{|l|}{ TB Knowledge } \\
\hline Good (8-10) & 3 & 1 \\
\hline Enough (5-7) & 6 & 8 \\
\hline Lacks $(<5)$ & 2 & 2 \\
\hline
\end{tabular}


From the data collected, the patients were classified into two groups, the delayed and not delayed. Patients in the delay category were the ones who experienced patient delay above 2 weeks. The data collected were analyzed with binary logistic regression method using SPSS. This test was to determine the effect of the independent variables that could contribute to the patient's delay behavior. The analysis result is shown in Table 2.

\section{DISCUSSION}

The gender ratio found in this study was 50:50, with 11 male and 11 female. This gender ratio is slightly different from WHO TB Global Report 2018. According to $\mathrm{WHO}$, in 2018, TB patients in Indonesia had a male:female ratio of 7:5. Gender ratios may differ in another country. For example, Pakistan and Peru have more female patients than the male ones in the same age range. ${ }^{8}$ Even so, there are other studies that have more male patients who have positive tuberculin test than the female ones. ${ }^{9}$

In this study, it was found that the number of patients spread evenly in each age group, with the youngest patient was 15 years old and the oldest patient was 68 years old. This result is not so different from another study conducted by Maesaroh in 2009 which mentioned that the youngest sample was 15 years old and the oldest sample was 60 years old. ${ }^{10}$ This indicates that TB can infect anyone within a wide range of ages. There are various factors that cause a high number of TB patients in Indonesia, some of them are high number of active smokers, malnutrition, diabetes, HIV, ${ }^{11}$ and also socioeconomic behavior, alcohol consumption, and air pollution. ${ }^{12}$ High number of geriatric TB patients is suspected due to vulnerability to TB infection and healing difficulty due to the drug's side effect; it is supported by other study which mentioned that geriatric age group also have a high morbidity number, especially if they also suffered from another comorbidity disease. ${ }^{13}$

The majority of the education level of the sample was high school graduates. However, there was no direct correlation between education level and TB infection risk. Education level is a not determinant factor in a country that has limited resources. ${ }^{14}$ Higher education levels, however, tend to make the patient avoid contact with HIV and have more awareness of their health condition. Patient's education level also affects the obedience of the treatment, ${ }^{15}$ which is proven with the data which stated that patients with a higher level of education have less dropout number than those who have a lower level of education.

It was found that the majority of the patients were unemployed, followed by entrepreneurs, with almost all patients had middle to low economy background. This finding is in line with several other studies which stated that people with low and unstable income are more vulnerable to TB infection than those with a guaranteed and stable economy; ${ }^{16}$ it is also supported by another study which stated that TB infection risk increased with poverty and unemployed people. ${ }^{17}$

Difficult access to get services from healthcare facilities can cause a delay in diagnosis and patient's treatment, which furthermore can cause an increase in incidence rate and TB transmission. ${ }^{18}$ In this study, it was found that the furthest patient's house was $15 \mathrm{~km}$ away from the health facility, with the median distance of $5.3 \mathrm{~km}$. This is considered as far, compared to a study conducted in Ethiopia in 2012 which stated the median distance between the patient's house and the health facility was 3.6 kilometers. The further the house distance is inversely proportional to Clinical Notification Rate (CNR) of TB. ${ }^{19}$ Higher CNR when the health facility is near does not mean more people are infected by TB, but more likely more TB suspects that have not checked yet can be diagnosed.

Patients can have various level of knowledge about TB, started from those that have minimal knowledge about TB until those who know well. In this study, the samples who had good knowledge about TB was only 4 people. The rest (14 people) only had elementary or minimal knowledge. This result is different from some other studies which mentioned that the majority of the sample had good knowledge about TB. ${ }^{10,20}$ This different finding is quite normal since it could be caused by the differences in the patients' backgrounds. Researchers have various opinions regarding the effect of knowledge. According to a study conducted by Wang, it said that the lack of patient's knowledge in recognizing TB symptoms was a significant factor that lead to TB diagnosis delay; ${ }^{21}$ meanwhile, according to Maftuhah, her study mentioned 
that there was no significant correlation between the

treatment. ${ }^{22}$ Aside from intensifying and socializing to the public, another solution that can be considered is giving education to the public using a health belief model that has proven effective to increase the patient's knowledge and self-care behavior of TB patients. ${ }^{23}$

In this study, it can be seen that the patients had a very varied range of patient delay duration, from 1 week until 4 months. The median of patient delay duration found in this study was 29 days. This result is quite similar to a study conducted in Ethiopia in 2018 which was 30 days. $^{24}$ The delay interval was quite poor, considering TB could transmit easily through the air which contained droplet from TB patients, and patients who already suffered from TB without medication could get worse.

As seen in Figure 5, the interval from the patient went to the clinic until the sputum sample was collected was mostly 0 day. This means that the sample was collected on the same day the patient came to the clinic, and the longest was 3 weeks apart. It was found that the median of the interval duration was 1.6 days.

The majority of the patients needed 1 day in order to wait until the sputum examination result came out, and the longest was 1 week of waiting. This data was obtained from the patient's answer, but when confirmed the laboratory staff said that sputum examination usually only needs 1 or 2 days, thus it is possible that the data anomaly of those who needed almost 1 week to wait for the result was due to other external factors, such as the clinic was not available (the TB clinic of PHC was only available on Monday and Thursday) or the patient did not collect the result on time. In this study, the median of waiting duration was 1.5 days.

The duration from the check result came out until the TB treatment varied, with the shortest was 0 day and the longest was 3 weeks. Still, the majority of the patients directly received TB treatments on the same day or 2 days after the result came out. Variation of the interval seen in Figure 7 was due to external factors, such as the clinic that was only available on Monday and Thursday, the patients who procrastinated the treatment, or other factors. In this study, the median from the test result came out until the treatment started was 3 days, ranging from 0 day until 3 weeks. patients' knowledge and the obedience of the patients'

Based on the analysis result with the binary logistic regression method (Table 6), the independent variable did not statistically proven to have an effect on patient delay behavior on society. This could be seen from no independent factors which had sig $<0.05$. The effect of the independent variable on the dependent variable which were not proven in this study could probably due to many factors, among others were the limited amount of sample and the difference between the delayed group and non-delayed group was not so distinct.

\section{CONCLUSION}

Duration of patient delay contributes significantly to the duration of diagnosis delay, with the median duration of 29 days, while system delay did not contribute much to the interval of diagnosis delay. In normal condition, the duration of system delay is only 3 days or less. The anomaly of system delay duration found in this study was due to external factors which varied widely and could not be calculated; among others were long holidays or the patients who forgot to go to the clinic on schedule. In this study, however, the independent variable did not statistically proven to affect patient delay behavior. This was probably caused by the difference between the delayed group and non-delayed group which was not so distinct and the limited amount of sample.

\section{REFERENCES}

1. Organization WH. Use of High Burden Country Lists for TB by WHO in the Post-2015 Era. Geneva, https://www.who.int/tb/publications/global_report/ high_tb_burdencountrylists2016-2020.pdf (2016).

2. Organization WH. Country Profiles for $30 \mathrm{High}$ TB Burden Countries. Geneva, https://www.who.int/tb/publications/global_report/ gtbr2017_annex2.pdf?ua=1 (2016).

3. Indonesia KKR. Profil Kesehatan Indonesia Tahun $2016 . \quad$ Jakarta, https://pusdatin.kemkes.go.id/resources/download/ pusdatin/profil-kesehatan-indonesia/Profil-

Kesehatan-Indonesia-2016.pdf (2017).

4. Golub JE, Bur S, Cronin WA, et al. Delayed Tuberculosis Diagnosis and Tuberculosis Transmission. Int J Tuberc lung Dis Off J Int Union against Tuberc Lung Dis 2006; 10: 24-30. 
5. Gebeyehu E, Azage M, Abeje G. Factors Associated with Patient's Delay in Tuberculosis Treatment in Bahir Dar City Administration, Northwest Ethiopia. Biomed Res Int 2014; 2014 : 701429.

6. Paramasivam S, Thomas B, Chandran $\mathrm{P}$, et al. Diagnostic Delay and Associated Factors among Patients with Pulmonary Tuberculosis in Kerala. $J$ Fam Med Prim care 2017; 6: 643-648.

7. Lin Y-H, Chen C-P, Chen P-Y, et al. Screening for Pulmonary Tuberculosis in Type 2 Diabetes Elderly: A Cross-Sectional Study in a Community Hospital. BMC Public Health 2015; 15: 3.

8. Boum Y 2nd, Atwine D, Orikiriza P, et al. Male Gender is Independently Associated with Pulmonary Tuberculosis among Sputum and NonSputum Producers People with Presumptive Tuberculosis in Southwestern Uganda. BMC Infect Dis 2014; 14: 638.

9. Herchline TE, Amorosa JK. Tuberculosis (TB). Medscape, https://emedicine.medscape.com/article/230802overview (2019).

10. Maesaroh S. Faktor-faktor yang Berhubungan dengan Kepatuhan Berobat Pasien Tuberkulosis Paru di Klinik Jakarta Respiratory Centre (JRC)/PPTI tahun 2009. Skripsi Progr Stud Ilmu Keperawatan FKIK UIN Syarif Hidayatullah Jakarta.

11. Organization WH. Global Tuberculosis Report 2018. Geneva, https://www.who.int/tb/publications/global_report/ gtbr2018_main_text_28Feb2019.pdf (2018).

12. Narasimhan P, Wood J, MacIntyre CR, et al. Risk Factors for Tuberculosis. Pulm Med 2013; 2013: 828939.

13. Wu Y-C, Lo H-Y, Yang S-L, et al. Comparing the Factors Correlated with Tuberculosis-Specific and Non-Tuberculosis-Specific Deaths in Different Age Groups among Tuberculosis-Related Deaths in Taiwan. PLoS One 2015; 10: e0118929.

14. Cohen GM, Werner L, Gengiah S, et al. Role of Education in HIV Clinical Outcomes in a Tuberculosis Endemic Setting. J Int Assoc Provid AIDS Care 2014; 13: 402-408.

15. Da Silva V, Tigeh S, Wirawan N, et al. The Relationship between Education, Job, and Family Income with TB Medication Dropouts in Timor-
Leste. Bali Med Journal; Vol 5, No 2 (Available online 1 August 2016), https://www.balimedicaljournal.org/index.php/bmj/ article/view/223 (2016).

16. Odone A, Crampin AC, Mwinuka V, et al. Association between Socioeconomic Position and Tuberculosis in a Large Population-Based Study in Rural Malawi. PLoS One 2013; 8: e77740.

17. Harling G, Ehrlich R, Myer L. The Social Epidemiology of Tuberculosis in South Africa: A Multilevel Analysis. Soc Sci Med 2008; 66: 492 505.

18. Hayward S, Harding RM, McShane $\mathrm{H}$, et al. Factors Influencing the Higher Incidence of Tuberculosis among Migrants and Ethnic Minorities in the UK. F1000Research 2018; 7: 461.

19. Dangisso MH, Datiko DG, Lindtjørn B. Accessibility to Tuberculosis Control Services and Tuberculosis Programme Performance in Southern Ethiopia. Glob Health Action 2015; 8: 29443.

20. Silvia Prihantana Sri ASW. Hubungan Pengetahuan dengan Tingkat Kepatuhan Pengobatan pada Pasien Tuberkulosis di RSUD Dr. Soehadi Prijonegoro Sragen. J Farm Sains dan Prakt 2016; 46-52.

21. Wang J, Fei Y, Shen H, et al. Gender Difference in Knowledge of Tuberculosis and Associated HealthCare Seeking Behaviors: A Cross-Sectional Study in a Rural Area of China. BMC Public Health 2008; 8: 354.

22. Maftuhah A. Hubungan Pengetahuan terhadap Tingkat Kepatuhan Pasien Tuberculosis di Balai Kesehatan Paru Masyarakat Provinsi Jawa Barat. J Kesehat Indra Husada 2018; 6: 1.

23. Jadgal KM, Nakhaei-Moghadam T, AlizadehSeiouki $\mathrm{H}$, et al. Impact of Educational Intervention on Patients Behavior with Smearpositive Pulmonary Tuberculosis: A Study Using the Health Belief Model. Mater Sociomed 2015; 27: 229-233.

24. Fuge TG, Bawore SG, Solomon DW, et al. Patient Delay in Seeking Tuberculosis Diagnosis and Associated Factors in Hadiya Zone, Southern Ethiopia. BMC Res Notes 2018; 11: 115. 